\title{
Extremely small genomes in two unrelated dipteran insects with shared early developmental traits
}

\author{
Urs Schmidt-Ott • Ab. Matteen Rafiqi • Klaus Sander • \\ J. Spencer Johnston
}

Received: 16 January 2009/Accepted: 4 March 2009/Published online: 24 March 2009

(C) The Author(s) 2009. This article is published with open access at Springerlink.com

\begin{abstract}
We discovered extremely small genomes (1C $\sim 100 \mathrm{Mb})$ in the dipteran insects Coboldia fuscipes (Scatopsidae) and Psychoda cinerea (Psychodidae). The small genomes of these species cannot be explained by a fast developmental rate, which has been shown to correlate with small genome sizes in animals and plants but might accommodate the combined effects of other developmental traits, including small egg size, thin blastoderm layer, and long-germ development.
\end{abstract}

Keywords Diptera - Genome size $\cdot$ Egg size $\cdot$ Blastoderm Pair-rule patterning $\cdot$ Flow cytometry

\section{Introduction}

Genome size evolution is a complex multifactorial process. However, in animals and plants, genome size often

Communicated by P. Simpson

U. Schmidt-Ott $(\bowtie) \cdot$ A. M. Rafiqi

Department of Organismal Biology and Anatomy,

University of Chicago,

CLSC 921B, 920 E. 58th Street,

Chicago, IL 60637, USA

e-mail: uschmid@uchicago.edu

K. Sander

Institut für Biologie 1, Albert-Ludwigs-Universität Freiburg,

Hauptstraße 1,

Freiburg 79104, Germany

e-mail: Klaus.Sander@biologie.uni-freiburg.de

J. S. Johnston

Department of Entomology, Texas A\&M University,

TAMU 2475,

College Station, TX 77843, USA

e-mail: spencerj@tamu.edu correlates with cell size and the rate of cell division (Gregory 2001; Gregory 2002). The coding genome of animals seems to impose a lower threshold at about $100 \mathrm{Mb}$ for the haploid (1C) genome; smaller genomes may require a substantive reduction of the coding genome (Lynch 2007). The 100-Mb threshold coincides for example with the genome size of Caenorhabdites elegans (Bennett et al. 2003), a very fast developing organism with about 19,000 protein-coding genes. The smallest insect genomes reported so far belong to highly specialized parasitic species including the louse Pediculus humanus $(1 \mathrm{C}=105 \mathrm{Mb}$; Johnston et al. 2007) and the strepsipteran Caenocholax fenyesi texensis $(1 \mathrm{C}=108 \mathrm{Mb}$; Johnston et al. 2004). The next to follow in size are the genomes of certain dipteran midges (Mayetiola destructor, Cecidomyidae; Prodiamesa olivacea, Chironomidae) with $1 \mathrm{C}>120 \mathrm{Mb}$ (Zacharias 1979; Petitpierre 1996; Johnston et al. 2004), but genome size estimates of other dipterans are distinctly larger (1C> $140 \mathrm{Mb}$, Gregory et al. 2007).

A recent study surveying the genome sizes of 67 drosophilid species provided evidence for a significant positive correlation between genome size and developmental time, which suggests that, as a rule, species with smaller genome sizes develop more quickly than those with larger genomes (Gregory and Johnston 2008). Another developmental factor, egg size, might influence the genome size of dipteran insects as well. Dipterans establish a molecular prepattern of the segmented body in the blastoderm, the monolayer of cells surrounding the yolk before the onset of gastrulation (long-germ development, Davis and Patel 2002). Pattern formation up to this stage proceeds through a cascade of spatially regulated transcription factors in which pair-rule genes, the first genes to become activated in a reiterated pattern of transverse stripes, allocate cells of the blastoderm to alternate segments (Pankratz and Jäckle 
1993). The number of stripes of a particular pair-rule gene that is synchronously expressed in the cellular blastoderm varies in Diptera between six and eight, but its minimal spacing (measured in cell diameters) is conserved across the taxon (our unpublished data and Bullock et al. 2004; Lott et al. 2007; Lemke and Schmidt-Ott 2009). Based on the apparent spatial requirements for synchronous pair-rule patterning in the cellular blastoderm, one might expect that dipterans with small eggs package blastoderm cells more tightly than dipterans with large eggs. In extreme cases, tighter packaging of blastoderm cells could potentially correlate with particularly small genome sizes (small nuclei). To explore this idea, we examined the blastoderms and genome sizes of Coboldia fuscipes (Scatopsidae), Psychoda cinerea (Psychodidae), and Chironomus riparius (Chironomidae), three unrelated slowly developing species with unusually small eggs $(<300 \mu \mathrm{m}$ long, cf. Table 1 and Hinton 1981; Ferrar 1987), and compared these species to Clogmia albipunctata (Psychodidae), a close relative of $P$. cinerea with an egg length of $\sim 400 \mu \mathrm{m}$ and to Drosophila melanogaster (egg length, 470-600 $\mu \mathrm{m}$, Lott et al. 2007).

\section{Materials and methods}

Flow cytometry

Genome sizes of $C$. fuscipes, $P$. cinerea, $C$. albipunctata, and $C$. riparius were estimated using brain nuclei and a propidium iodide flow cytometry protocol (Bennett et al.
2003; DeSalle et al. 2005; Gregory and Johnston 2008). Briefly, sample and standard were ground together and passed through a $50-\mu \mathrm{m}$ filter, stained with $50 \mathrm{ppm}$ of propidium iodide and run (after $30 \mathrm{~min}$ in the cold and dark) in a Beckman Coulter Elite flow cytometer with the laser emitting $25 \mathrm{~mW}$ of exciting light at $488 \mathrm{~nm}$. Fluorescent nuclei were detected using a high bandpass filter $(615 \mathrm{~nm})$. $P$. cinerea was prepared as above at the Jodrell Laboratory, RBG Kew, UK and run on a Partek CyFlow available at that laboratory (514-nm laser excitation, 25-mW, long pass filter). DNA content was determined by multiplying the ratio of the mean peak fluorescence of the $2 \mathrm{C}$ sample/mean peak of the standard with $175 \mathrm{Mb}$, the genome size of the sequenced strain of D. melanogaster anchored against the fully sequenced $C$. elegans strain (Bennett et al. 2003).

\section{Blastoderm measurements}

To determine the number of transverse cell rows along the anteroposterior axis, late blastoderm embryos of $C$. fuscipes, C. riparius, C. albipunctata, and D. melanogaster were fixed with formaldehyde, stained with 4',6-diamidino2-phenylindole or Draq5, and examined with a confocal microscope. Internuclear distances were measured using Image J software. For $P$. cinerea, approximate internuclear distances were estimated by multiplying the length of eggs with an empirically determined correction factor (1.1, estimated from the other species) and dividing the product by the number of nuclear columns.

Table 1 Egg length, blastoderm, and genome sizes

\begin{tabular}{|c|c|c|c|c|c|c|}
\hline Taxon & Egg-length & $\begin{array}{l}\text { Nuclear Columns } \\
\text { (AP-Axis) }\end{array}$ & $\begin{array}{l}\text { Inter-Nuclear Distance } \\
\text { Measurements }\end{array}$ & Haploid Genome Size (SE) & Sex & $\mathrm{N}$ \\
\hline \multicolumn{7}{|c|}{ Chironomus riparius (Chironomidae) } \\
\hline Live (SE) & $258 \mu \mathrm{m}(2.2)$ & $58.8(1.3)$ & $4.87 \mu \mathrm{m}(0.15)$ & $196.2 \mathrm{Mb}(1.0)$ & $\mathrm{F}$ & 9 \\
\hline Fixed (SE) & $258 \mu \mathrm{m}(4.8)$ & & & 194.3 Mb (1.1) & M & 8 \\
\hline \multicolumn{7}{|c|}{ Coboldia fuscipes (Scatopsidae) } \\
\hline Live (SE) & $252 \mu \mathrm{m}(1.7)$ & $53.5(0.6)$ & $4.65 \mu \mathrm{m}(0.08)$ & 102.2 $\mathrm{Mb}(0.3)$ & $\mathrm{F}$ & 5 \\
\hline Fixed (SE) & $229 \mu \mathrm{m}(2.4)$ & & & $100.4 \mathrm{Mb}(0.3)$ & M & 9 \\
\hline \multicolumn{7}{|c|}{ Psychoda cinerea (Psychodidae) } \\
\hline $\begin{array}{l}\text { Live (SE) } \\
\text { Fixed (SE) }\end{array}$ & $\begin{array}{l}\sim 235 \mu \mathrm{m} \\
225 \mu \mathrm{m}(5.9)\end{array}$ & $59.3(0.7)$ & $4.19 \mu \mathrm{m}(0.08)$ & $100.7 \mathrm{Mb}(0.0)$ & n.d. & 3 \\
\hline \multicolumn{7}{|c|}{ Clogmia albipunctata (Psychodidae) } \\
\hline Live (SE) & $432 \mu \mathrm{m}(2.3)$ & $75.0(1.5)$ & $5.88 \mu \mathrm{m}(0.10)$ & $316.6 \mathrm{Mb}(1.4)$ & $\mathrm{F}$ & 3 \\
\hline Fixed (SE) & $401 \mu \mathrm{m}(6.0)$ & & & $316.6 \mathrm{Mb}(0.5)$ & M & 2 \\
\hline \multicolumn{7}{|c|}{ Drosophila melanogaster (Drosophilidae) } \\
\hline $\begin{array}{l}\text { Live (SE) } \\
\text { Fixed (SE) }\end{array}$ & $\begin{array}{l}497 \mu \mathrm{m}(3.6) \\
462 \mu \mathrm{m}(9.6)\end{array}$ & $84.4(1.1)$ & $6.18 \mu \mathrm{m}(0.11)$ & $175 \mathrm{Mb}$ & $\mathrm{F}$ & - \\
\hline
\end{tabular}

Egg lengths of formaldehyde-fixed material was treated with commercial bleach, which removes the outer chorion

$F$ female, $M$ male, n.d. not determined, $S E$ (numbers in brackets), standard error 


\section{Results and discussion}

To estimate the number and packaging density of blastoderm cells, we counted in each species the number of transverse rows of nuclei from the anterior to the posterior pole (Table 1). The number of rows in the cellular blastoderms of $C$. fuscipes ( 54), P. cinerea ( $\sim 59)$, and $C$. riparius $(\sim 60)$ was significantly lower than in C. albipunctata $(\sim 75)$ and D. melanogaster $(\sim 86)$. The average internuclear distances were $\sim 4.7 \mu \mathrm{m}$ in $C$. fuscipes, $\sim 4.2 \mu \mathrm{m}$ in P. cinerea, and $\sim 4.4 \mu \mathrm{m}$ in $C$. riparius, compared to $\sim 5.9 \mu \mathrm{m}$ in $C$. albipunctata and $\sim 6.2 \mu \mathrm{m}$ in D. melanogaster. Thus, the small size of $C$. fuscipes, $P$. cinerea, and $C$. riparius eggs correlates with both a reduction of the number of blastoderm cells and tighter packaging of these cells.

To estimate genome sizes, we used flow cytometry with D. melanogaster as standard $(1 \mathrm{C}=175 \mathrm{Mb}$, Bennett et al. 2003). We estimated haploid genome sizes of $\sim 100 \mathrm{Mb}$ for $C$. fuscipes and $P$. cinerea, of $\sim 200 \mathrm{Mb}$ for $C$. riparius, and of more than $300 \mathrm{Mb}$ for C. albipunctata (Fig. 1, Table 1). The small genome sizes of the cosmopolitan species $C$. fuscipes and $P$. cinerea seem to have evolved independently given that the two species are not closely related and that much larger genomes have been estimated for other psychodids, including C. albipunctata (this study), Telmatoscopus meridionalis (referenced in Gregory et al. 2007), Phlebotomus papatasi and Lutzomyia longipalpis (J. S. J., unpublished data). Furthermore, the small genome sizes of $C$. fuscipes and P. cinerea cannot be explained by an unusually fast developmental rate. At $25^{\circ} \mathrm{C}$, the tiny eggs of $C$. fuscipes hatched as larvae after $\sim 66 \mathrm{~h}(24 \mathrm{~h}$ in D. melanogaster), pupated after $\sim 15$ days ( 5 days in $D$. melanogaster), and emerged as adults after a total developmental time of $\sim 19$ days (see also Choi et al. 2000). Mating was observed on the following day and egg deposition 2 days after the adults had emerged from the pupal casing. The females deposited a single package of hundreds of eggs, which started development immediately after deposition. Thus, the total generation time of $C$. fuscipes was about 3 weeks ( $\sim 12$ days in D. melanogaster). In $P$. cinerea, embryogenesis lasted about 3 days (measured at $24^{\circ} \mathrm{C}$ ). The eggs matured simultaneously (about 140-190, Sander 1985), and the entire life cycle lasted about 2-3 weeks. In summary, both species, like two other species measured in this study, C. albipunctata (embryogenesis, $\sim 2$ days; life cycle, 22 days at $25^{\circ} \mathrm{C}$ ) and C. riparius (embryogenesis, $\sim 2$ days; life cycle, $3-4$ weeks at $25^{\circ} \mathrm{C}$ ), developed significantly slower than D. melanogaster.

While the genome size estimates of $C$. fuscipes and $P$. cinerea are consistent with our starting hypothesis that dipterans with extremely small eggs tend to have very small genomes, the twofold larger genome size of $C$. riparius (which shares a similar egg length and packaging density of
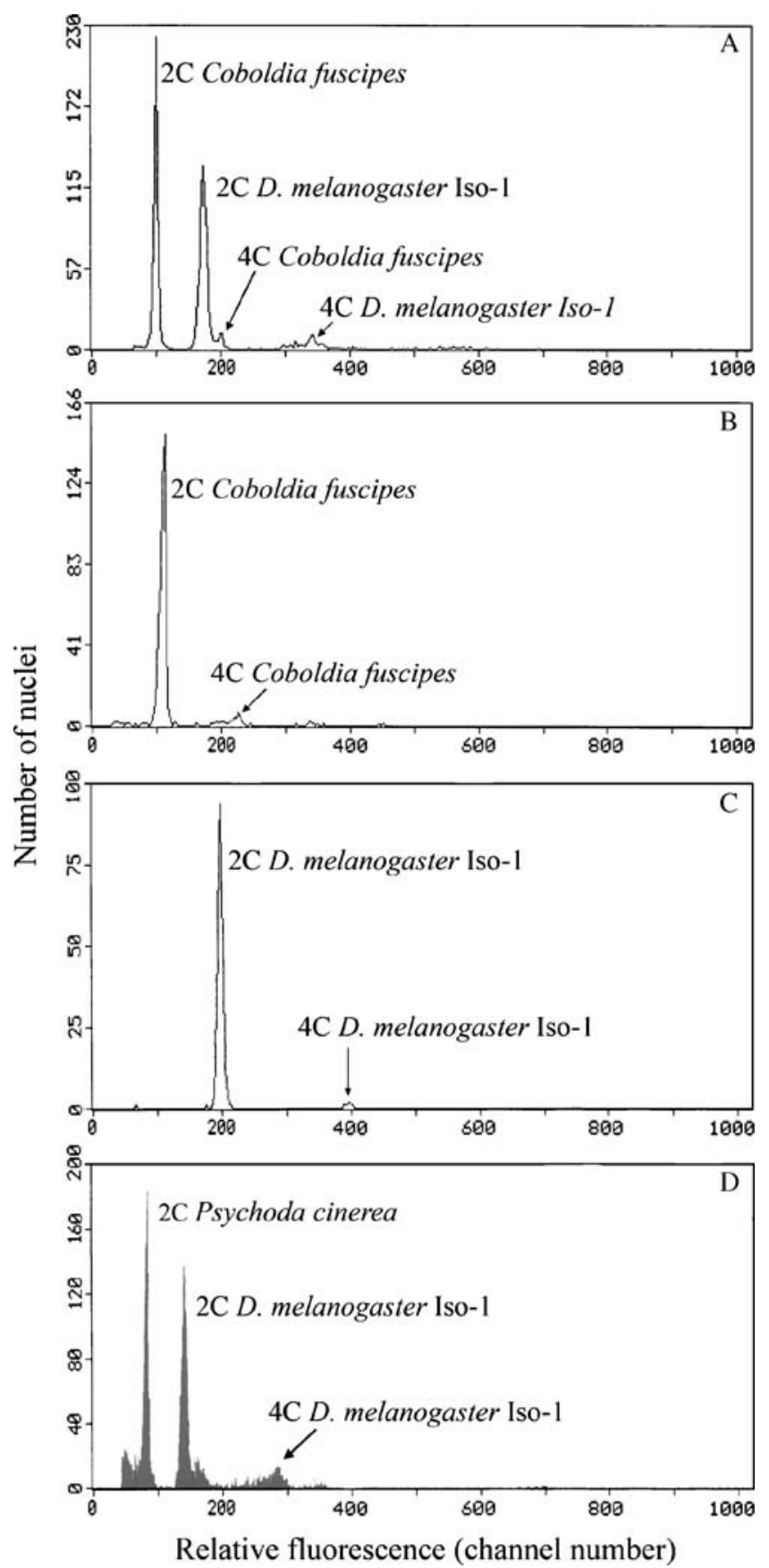

Fig. 1 Sample histograms from the flow cytometric analysis. Diagrams show the number of nuclei with differing levels of red fluorescence corresponding to binding of propidium iodide to the DNA of 2C and 4C nuclei. a Co-prepared head cells of $C$. fuscipes and D. melanogaster Iso-1 $(1 \mathrm{C}=175 \mathrm{Mb})$. b Head cells of female $C$. fuscipes. On a $\log / \log$ scale, smaller peaks were not detected, indicating that the $2 \mathrm{C}$ peak of $C$. fuscipes is correctly identified. Ninety-six percent of the head cells were $2 \mathrm{C}$ and $4 \% 4 \mathrm{C}$. We obtained reproducible results $30 \mathrm{~min}$ and $6 \mathrm{~h}$ after staining the cells. DNA degradation was not observed. c Head cells of female D. melanogaster Iso-1. d Co-prepared head cells of $P$. cinerea and D. melanogaster Iso-1 
blastoderm cells) indicates that small egg size is not sufficient to explain the minute genomes of $C$. fuscipes and $P$. cinerea. To explain the differences in genome size between these species, we propose that upper thresholds also depend on the blastoderm type. Many lower dipterans (including $C$. fuscipes, $P$. cinerea, and $C$. albipunctata) develop a very thin blastoderm, in which the individual cells are essentially filled by the nucleus, while culicomorphan mosquitoes (including $C$. riparius) and cyclorrhaphan flies (including D. melanogaster) form a thickened blastoderm with a much smaller nucleus to cytoplasm ratio (Anderson 1972; Sander 2000; Bullock et al. 2004), which might attenuate constraints on the DNA content of blastoderm nuclei in species with small eggs.

In summary, we have identified two unrelated dipterans with extremely small genomes that share small egg size, thin blastoderm, and high packaging density of blastoderm cells. In both species, the advantages of synchronous pairrule patterning (to reduce developmental time) and small egg size (to maximize offspring, in both species all eggs mature simultaneously and compete for space in the female abdomen) might have been traded against genome size. To put this new idea to a rigorous test, it will be necessary to search systematically for dipterans with tiny eggs, thin blastoderm, and slow development and to determine their genome sizes.

Acknowledgments We thank Ilia Leitch for use of cytometry facilities at the Jodrell laboratory, RBG Kew, Giorgios Pyrowolakis at the University of Freiburg for logistical help, Steffen Lemke for comments on the manuscript, and Alison Bockoven for help with preparing the figure. Funding was provided by an NHGRI subcontract (J. S. J.) and NSF (U. S.-O.).

Open Access This article is distributed under the terms of the Creative Commons Attribution Noncommercial License which permits any noncommercial use, distribution, and reproduction in any medium, provided the original author(s) and source are credited.

\section{References}

Anderson DT (1972) The development of holometabolous insects. In: Counce SJ, Waddington $\mathrm{CH}$ (eds) Developmental systems: insects. Academic, London, pp 165-242

Bennett MD, Leitch IJ, Price HJ, Johnston JS (2003) Comparisons with Caenorhabditis $(100 \mathrm{Mb})$ and Drosophila $(175 \mathrm{Mb})$ using flow cytometry show genome size in Arabidopsis to be $157 \mathrm{Mb}$ and thus $25 \%$ larger than the Arabidopsis initiative estimate of $125 \mathrm{Mb}$. Ann Bot 91:547-557

Bullock SL, Stauber M, Prell A, Hughes JR, Ish-Horowicz D, Schmidt-Ott U (2004) Differential cytoplasmic mRNA localization adjusts pair-rule transcription factor activity to cytoarchitecture in dipteran evolution. Development 131:4251-4261

Choi K-H, Kim S-R, Cho E-S, Yang W-J, Jin B-R (2000) Developmental and life history characteristics of the oyster mushroom fly, Coboldia fuscipes (Diptera: Scatopsidae). Appl Entomol Zool 35:495-498

Davis G, Patel N (2002) Short, long, and beyond: molecular and embryological approaches to insect segmentation. Annu Rev Entomol 47:669-699

DeSalle R, Gregory TR, Johnston JS (2005) Preparation of samples for comparative studies of arthropod chromosomes: visualization, in situ hybridization, and genome size estimation. Methods Enzymol 395:460-488

Ferrar P (1987) A guide to the breeding habits and immature stages of Diptera Cyclorrhapha. Entomonograph 8:907

Gregory TR (2001) Coincidence, coevolution, or causation? DNA content, cell size, and the C-value enigma. Biol Rev Camb Philos Soc 76:65-101

Gregory TR (2002) Genome size and developmental complexity. Genetica 115:131-146

Gregory TR, Johnston JS (2008) Genome size diversity in the family Drosophilidae. Heredity 101:228-238

Gregory TR, Nicol JA, Tamm H, Kullman B, Kullman K, Leitch IJ, Murray BG, Kapraun DF, Greilhuber J, Bennett MD (2007) Eukaryotic genome size databases. Nucleic Acids Res 35:D332-338

Hinton HE (1981) Biology of insect eggs. Pergamon Press, Oxford

Johnston JS, Ross LD, Bean L, Hughes DP, Kathirithamby J (2004) Tiny genomes and endoreduplication in Strepsiptera. Insect Mol Biol 13:581-585

Johnston JS, Yoon KS, Strycharz JP, Pittendrigh BR, Clark JM (2007) Body lice and head lice (Anoplura: Pediculidae) have the smallest genomes of any hemimetabolous insect reported to date. J Med Entomol 44:1009-1012

Lemke S, Schmidt-Ott U (2009) Evidence for a composite anterior determinant in the hover fly Episyrphus balteatus (Syrphidae), a cyclorrhaphan fly with an anterodorsal serosa anlage. Development 136:117-127

Lott SE, Kreitman M, Palsson A, Alekseeva E, Ludwig MZ (2007) Canalization of segmentation and its evolution in Drosophila. Proc Natl Acad Sci U S A 104:10926-10931

Lynch M (2007) The origins of genome architecture. Sinauer, Sunderland, MA, p 494

Pankratz MJ, Jäckle H (1993) Blastoderm segmentation. In: Bate M, Martinez-Arias A (eds) The development of Drosophila melanogaster. Cold Spring Harbor Laboratory Press, Cold Spring Harbor, pp 467-516

Petitpierre E (1996) Molecular cytogenetics and taxonomy of insects, with particular reference to the Coleoptera. Int J Insect Morphol Embryol 25:115-133

Sander K (1985) Experimental egg activation in lower dipterans (Psychoda, Smittia) by low osmolarity. Int J Invertebr Reprod Dev 8:175-183

Sander K (2000) Chironomid embryology in the 19th century: Insights and errors of its pioneers, especially August Weismann (1834 1914), and some 20th century sequels. In: Hoffrichter O (ed) Late 20th century research on Chironomidae: an anthology from the 13th international symposium on Chironomidae. Aachen, Shaker Verlag, pp 1-16

Zacharias H (1979) Underreplication of a polytene chromosome arm in the chironomid Prodiamesa olivacea. Chromosoma 72:23-51 